\title{
Proceeding
}

Supplementary Issue: Summer Conferences of Sports Science. First International Conference in Iraq on Sport for Peace, 4 April 2019. Baghdad Science Institute, Baghdad, Iraq.

\section{The effect of disciplinary background and sporting history of Premier League football players on sport legal awareness}

\author{
MAHDI AZIMI ${ }^{1}$, MONA TORKAMAN², SEYED AMIR REZA HOSSEINIPOUR RAFSANJANI ${ }^{3}$ \\ ${ }^{1}$ Kerman Azad University, Islamic Republic of Iran \\ ${ }^{2}$ Qeshm Branch, Research Sciences University, Islamic Republic of Iran \\ ${ }^{3}$ Kish International University, Islamic Republic of Iran
}

\begin{abstract}
The purpose of this study was to investigate the relationship between disciplinary background and sporting history of Premier League football players on their awareness of sports rights. In this study, descriptiveanalytical method and Spearman correlation coefficient were used. Questionnaires about variables were used to identify the sample group and the main questions about players' legal awareness were used for data collection. The results showed that Pearson correlation coefficient was 0.107, Spearman correlation coefficient was 0.204 and Kendall correlation coefficient was 0.139 and significant was 0.88 . There is no relationship between awareness of sports law and the history of sports in the Premier League. Based on the results of correlation coefficient and investigation of the relationship of players' disciplinary background with sport rights awareness the test statistic value is -1.73 and $p$-value is 0.84 , so the null hypothesis is not rejected at 0.05 level and therefore between sport rights awareness and No disciplinary record found. Keywords: Premier League players; Sports rights; Legal awareness; Disciplinary background; Game history.
\end{abstract}

Cite this article as:

Azimi, M., Torkaman, M., \& Rafsanjani, S.A.R.H. (2019). The effect of disciplinary background and sporting history of Premier League football players on sport legal awareness. Journal of Human Sport and Exercise, 14(5proc), S2084-S2090. doi:https://doi.org/10.14198/jhse.2019.14.Proc5.29

Corresponding author. Kerman Azad University, Islamic Republic of Iran.

E-mail: Fersh.alizadeht@gmail.com

Supplementary Issue: Summer Conferences of Sports Science. First International Conference in Iraq on Sport for Peace, 4 April 2019. Baghdad Science Institute, Baghdad, Iraq.

JOURNAL OF HUMAN SPORT \& EXERCISE ISSN 1988-5202

(c) Faculty of Education. University of Alicante

doi:10.14198/jhse.2019.14.Proc5.29 


\section{INTRODUCTION}

Due to the limitations of sports fields in the past, the number of injuries, injuries and conflicts is low. In today's society, as sport has expanded into various disciplines, the role of sport law has become more intense, requiring that each sport has a set of rules that make it available to federations or boards and monitor errors. It can be caused by sports. The subject of sports rights is all violations that occur in the field of sports and somehow harm the rights of others. The legal analysis of these violations will be dealt with as if they are unlawful, classified as criminal or quasi-criminal, and will ultimately be a study of society's reaction to such violations. These reactions are sometimes used as punishments such as cash, flogging, imprisonment, deprivation of social rights, and even the execution of the offender, and the offender will be liable for damages if convicted. Given that the incident seems inseparable from the sport, it is definitely not avoidable. Therefore, the birth date of sports rights should be regarded as the period when human beings have accepted sport as one of the most important institutions of their social life. But the quality and quantity of each society depends on their civilization and culture, even if it is the same today (Aghaeinia, 2010).

Sports incidents in the context of sports law are all offenses and quasi-offenses committed by athletes, teachers, coaches, managers, spectators, makers and producers of supplies and equipment, directly or indirectly, in connection with the sport. Takes. The subject of these events may be the health, life, property, dignity, dignity and other legal rights of individuals who are present in the sport in some way. In general, in all countries of the world, sport enjoys special public support, because the goals of sport are in fact the training of generations, well-being, empowerment, vitality, health and, finally, the preparation of the most important pillar of development, that is, human beings, and not political and economic aspects. Its societies have simply enacted very specific laws and privileges for the sole purpose of giving support to this activity and for this very reason. Sometimes these concessions are different; sometimes in the form of explicit rules and sometimes implicitly and sometimes in the form of judicial procedures for sport operations (Aghaeinia, 2010; Berciano et al., 2017). Despite the importance of sports legal issues, the Islamic Penal Code of Iran has addressed only one article in Article 59, the latest revised version of which stipulates in 1991: The regulations do not apply to that sport, and these regulations do not constitute an offense to the law, not a crime (Zeraat, 2007). The basis for the legitimacy of accidents resulting from sporting activities must be documented by law allowing that accidents and acts that are subject to the rules of that sport cannot be prosecuted and prosecuted. Subject to the provisions of this article, if the incident resulting from a sporting activity is not in breach of the rules of that sport discipline and does not conflict with the law, it shall only be liable to criminal liability arising from the act or omission of the act, But the article does not make any comment on the fulfilment or delinquency of the liability. However, some jurists, ("Katouzian, 2009: Out-of-Contract Requirements: 407", believe that sports blame is a concept that, by the general rules of civil liability, cannot be attributed to the exercise of legal responsibility and the responsibility of the sport. Counted and studied separately. " Therefore, unlike other social relations in the field of sports law, the mere association of the three elements of civic responsibility, namely the loss community, the harmful act and the causal relationship, is not sufficient, and with the exception of the first pillar, the loss defect, with one exception. We are faced with this area and, contrary to the general rule governing civil liability, in the field of sports law, only those damages to persons during sports operations with the other two pillars of civil liability can be claimed in customary terms. Sport can be a result of unusual and dangerous behaviour (Ahmadi,2008; Sheralieva,2016). With regard to the social foundations, community interests, it seems more appropriate to engage people in sports activities and to prevent their tendency, especially the younger generation, to deviations and anti-values, a recent theory that ultimately Tends to support athletes who, in violation of the laws and regulations, make it easier for others to approach the community in a healthy way, without violating the laws or regulations. Despite the importance of the sports rights issue and the need to pay attention to it, 
very little research has been done in this area. Ghabeljoo examined the insurance coverage of football players and concluded that the quality of medical services, delays in payments, tariffs, lack of an institution or committee for the control and evaluation of services provided to individuals can be pointed out. (Foroughipour,2004) examined the level of familiarity of sports coaches, teachers, and managers with the rights of sport in Tehran and the presentation of its educational strategies. The results of this study showed that all three groups of coaches, teachers and sport managers are not familiar with the subject of sports law. (Ahmadi,2008) compared the insurance coverage of Iranian professional football players and the professional league of Japan. The results of this study showed that in both leagues the law and regulations in the league paid attention to the health insurance of the players, but at the implementation stage, compared to the Japanese league, little attention was paid to this. In this regard, the present study aims to describe and examine the relationship between the awareness of the sporting rights of the Premier League players with their athletic background, and the degree of the relationship between the awareness of the sporting rights of the Premier League players with their disciplinary unprecedented discipline.

\section{RESEARCH QUESTIONS}

For the purpose of this review, and in order to achieve it, the following questions have been posed:

1. Is there a meaningful relationship between the level of awareness of players' sports rights and their athletic background (playing experience)?

2. Is there a significant relationship between the level of awareness of players' sports rights and their disciplinary background?

\section{METHODOLOGY}

The research method was survey research in which library study, Delphi technique and questionnaire were used to collect the required information. The statistical population includes the first division soccer players of the country in 2012. These include 324 people. The figures are based on statistics from the AFC. In this research, as community members are distributed within teams, random sampling is used (Elmes, 2018). This means that the information and opinions of the soccer players of the top ten national teams (180 people) were collected. This sample size is obtained by the method of sample size determination by maximum error method. Sports Rights Awareness Questionnaire: A questionnaire was used to measure players' knowledge of sports rights. This questionnaire measures the level of legal awareness of players in sports law in three areas: contracts, disciplinary bylaws and basic issues of sports law. The validity of the questionnaire was 0.94. For collecting data, 190 questionnaires were distributed among the first league football players and finally after 2 months, 180 questionnaires were collected. Data analysis was performed at two levels of descriptive and inferential statistics. In the descriptive section, the research data were described using mean, median, fashion, frequency, percentage of frequency. In order to correlate between variables, inferential statistical tests such as regression, Kendall, Spearman, and distribution graphs were used. All statistical analyses were performed by SPSS software.

\section{FINDINGS}

Descriptive findings related to demographic characteristics of the sample indicated that among 76 players studied, 71 indicated age of their sport, 3 of them were $4(\%)$ less than 5 years, $22(31(5 \%) 10$ years and 27 patients (38\% 11 to 15 years and 17 persons (24\% 16 to 20 years and 2 patients $3(\%)$ ) above 20 years. Of the 76 players surveyed, 68 responded that $14(21 \%)$ had been summoned to one discipline and $54(79 \%)$ had no disciplinary background. 
Table 1. Frequency distribution of players' disciplinary background.

\begin{tabular}{|l|l|l|l|l|}
\hline $\begin{array}{l}\text { Have you been summoned to } \\
\text { the Disciplinary Committee? }\end{array}$ & Frequency & Percent & Respondent percent \\
\hline \multirow{3}{*}{ Respondent } & Yes & 33 & 18.4 & 21 \\
\cline { 2 - 5 } & No & 128 & 71.1 & 79 \\
\cline { 2 - 5 } & Total & 161 & 89.5 & 100 \\
\hline Unanswered & 19 & 10.5 & - \\
\hline Total & 180 & 100 & - \\
\hline
\end{tabular}

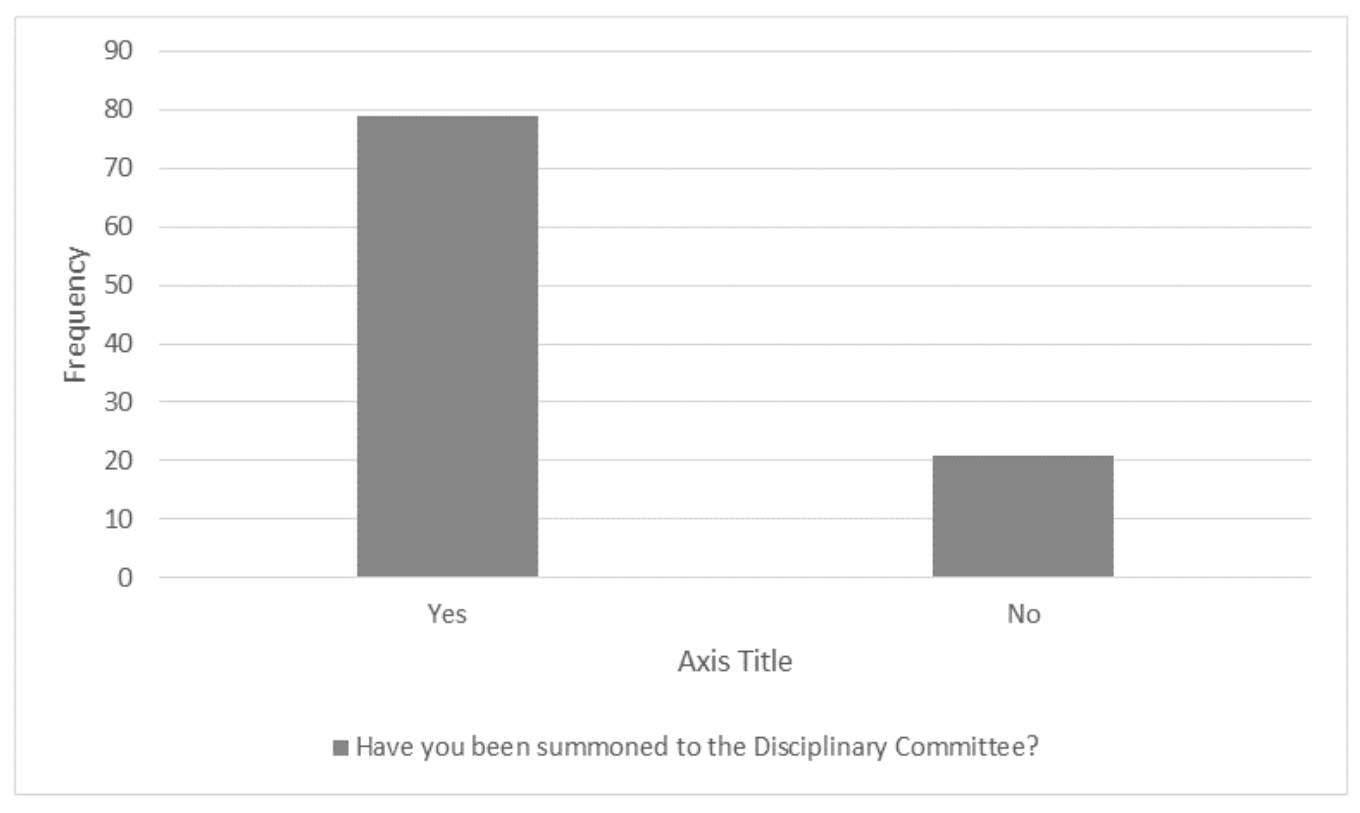

Figure 1. Percentage of players' disciplinary backgrounds.

Descriptive statistics on the level of legal awareness of sports law among the Premier League players by examining the varied legal awareness and its three dimensions (basic issues and principles of sports law, discipline provisions, contract discussions and players' consent) The mean awareness was $121.86 \%$, with a standard deviation of 22.97. Inferential statistics section was used to investigate the research questions. Correlation coefficient tests were used to investigate the research questions and hypotheses.

\section{FINDINGS RELATED TO THE FIRST QUESTION AND HYPOTHESIS}

Correlation tests of the first question whether there is a relationship between legal awareness and players' athletic background? Correlation test was used to test this hypothesis based on players' opinions. In this test, the assumption of zero and the opposite assumption are as follows: Assumption of zero: There is no relationship between awareness of sports rights and athletic background of Premier League players. The correlation coefficient between the two variables of awareness of sports law and sporting history of Premier League players is zero. The premise was that there was a relationship between awareness of sports rights and the history of the Premier League. The correlation coefficient between the two variables of awareness of sport rights and sport history of the Iranian Premier League players is zero. 
Table 2. Correlation coefficient to examine the relationship between players' athletic background and awareness of sports rights.

\begin{tabular}{|l|l|}
\hline Pearson correlation coefficient & 0.107 \\
\hline Spearman correlation coefficient & 0.204 \\
\hline Kendall correlation coefficient & 0.139 \\
\hline Number & 76 \\
\hline$P$ value & 0.088 \\
\hline
\end{tabular}

Relationship between players' athletic experience and awareness of sports rights showed that out of 76 players, Pearson correlation coefficient was 0.107 , Spearman correlation coefficient was 0.204 and Kendall correlation coefficient was 0.139 and $p$ - value was 0.088 . Therefore, the null hypothesis is not rejected at the 0.05 level. There is no relationship between awareness of sports rights and athletic background in the Premier League. (The correlation coefficient between the two variables of awareness of sport rights with the sport history of the Premier League players is zero.) The positive correlation coefficient indicates a direct relationship between the two variables of awareness of sport rights with sport history. This means that as the amount of the variable of athletic history increases, so does the level of awareness of athletic rights. The following distribution charts also confirm this. Kruskal-Wallis test was used for further investigation (Beheshti,2005).

Table 3. Statistics of players with legal awareness.

\begin{tabular}{|l|l|}
\hline Statistics & 5.696 \\
\hline Number & 76 \\
\hline$p$-value & 0.223 \\
\hline Sig. & 0.05 \\
\hline
\end{tabular}

Based on the results of 76 players, the test statistic value is 5.696 and the $p$ value is 0.233 , so the null hypothesis is rejected at the 0.05 level. There is no relationship between awareness of sports rights and athletic background in the Iranian Premier League. (The variable distribution of sport rights awareness is similar for players at different levels of their sporting background. As noted, as sporting history increases, so does legal awareness.

\section{FINDINGS RELATED TO THE SECOND QUESTION AND HYPOTHESIS}

Correlation tests for the second question of whether there is a relationship between legal awareness and players' disciplinary background. Correlation test was used to test this hypothesis based on players' opinions. In this test, the null hypothesis and the opposite hypothesis are as follows: null hypothesis: There is no relationship between awareness of sports rights and the disciplinary background of the Iranian Premier League players (Chalabi,2006). The correlation coefficient between the two variables of sport legal awareness and education of Premier League players is zero.

Table 4. Relationship of players' disciplinary backgrounds with awareness of sports rights.

\begin{tabular}{|l|l|}
\hline Statistics & 11.762 \\
\hline Number & 76 \\
\hline$p$-value & 0.008 \\
\hline Sig. & 0.05 \\
\hline
\end{tabular}


Based on the results of 76 players, the test statistic value is -1.73 and $p$-value is 0.084 , so the null hypothesis is not rejected at the 0.05 level. There is no relationship between awareness of sports rights and education of Premier League players. The variable distribution of awareness of sports rights is the same for players who have been summoned to a disciplinary committee or not. The box diagram below also confirms this (Zadeh Jafari,2015).

\section{CONCLUSION}

Based on a general summary, the results of this study can be summarized as follows from the research hypotheses. Is there a relationship between awareness of sports rights and players' athletic background? According to the results of 180 players, Pearson correlation coefficient 0.107 , Spearman correlation coefficient 0.204 , Kendall correlation coefficient 0.139 and significant value 0.88 , so the null hypothesis is not rejected at 0.05 . There is no relationship between awareness of sports law and the history of sports in the Premier League. The correlation coefficient between the two variables of sport legal awareness and sporting history of the premier league players was zero. The results of the first hypothesis of the study are consistent with the findings of Binan and Kashef that there was a significant difference between the views of teachers and those who had a moderate to high level of experience (15 years or more). Legal, more nobility, no match. In the second question, "is there a relationship between the awareness of sports rights and the disciplinary background of the players?", based on the results of 180 players, the test statistic value is -1.73 - a significant value of 0.04 , so the null hypothesis is not rejected at the 0.05 level. There is no relationship between sports legal awareness and the disciplinary background of the Iranian Premier League players. (The same distribution of sports legal awareness is similar for players who have been summoned to a disciplinary committee). Due to the high importance of players legal awareness, it is recommended that other researchers investigate the impact of external factors on the sport system that increase players' legal awareness. Also, given the results of the assumptions, it is advisable to conduct this research at the junior high. It is also suggested that researchers research the consequences of the lack of legal awareness of the players.

\section{REFERENCES}

Aghaeinia (2010). Sports Law, Sports and Its Legal Responsibilities, Quantity Publications.

Ahmadi (2008). Investigating insurance coverage of Iranian professional football players and comparing it with Japanese professional league.

Beheshti, Ahmad (2005). The Basics of Physical Education in Islam.

Berciano, A., Jiménez-Gestal, C., \& Salgado, M. (2017). Kindergartners' Use of Symbols in the Semiotic Representation of 3-Dimensional Changes. International Electronic Journal of Mathematics Education, 12(3), 311-331.

Chalabi (2006). An Introduction to Sports Law and the General Rules of Penal Law, Bamdad Book Publishing.

Elmes, D. (2018). Coach-player communications: an analysis of top-level coaching discourse at a shortterm ice hockey camp. Humanities \& Social Sciences Reviews, 6(2), 44-51. https://doi.org/10.18510/hssr.2018.626

Foroughipour (2004). Knowledge of coaches, teachers and sports managers about sports rights, thesis. Katouzian, N. (2009) Introduction to Law Science, Publishing Co., Tehran, Sixty-nine.

Sheralieva, M. (2016). Problem Of Irony And Intertextuality. UCT Journal of Social Sciences and Humanities Research, 4(3), 22-25. 
Zadeh Jafari, N., Noorai, T. And Puranjebar, M.S. (2015). A Survey on the Knowledge of Sport Rights among the Experts of Sport Committees and Kerman Youth and Sport Directorate General. National Conference on Achievements in Sport Science and Health. 1396, Volume 1.

Zeraat, Abbas (2007). Islamic Penal Code in the present order.

\section{(c) $(7) \odot$}

This work is licensed under a Attribution-NonCommercial-NoDerivatives 4.0 International (CC BY-NC-ND 4.0). 